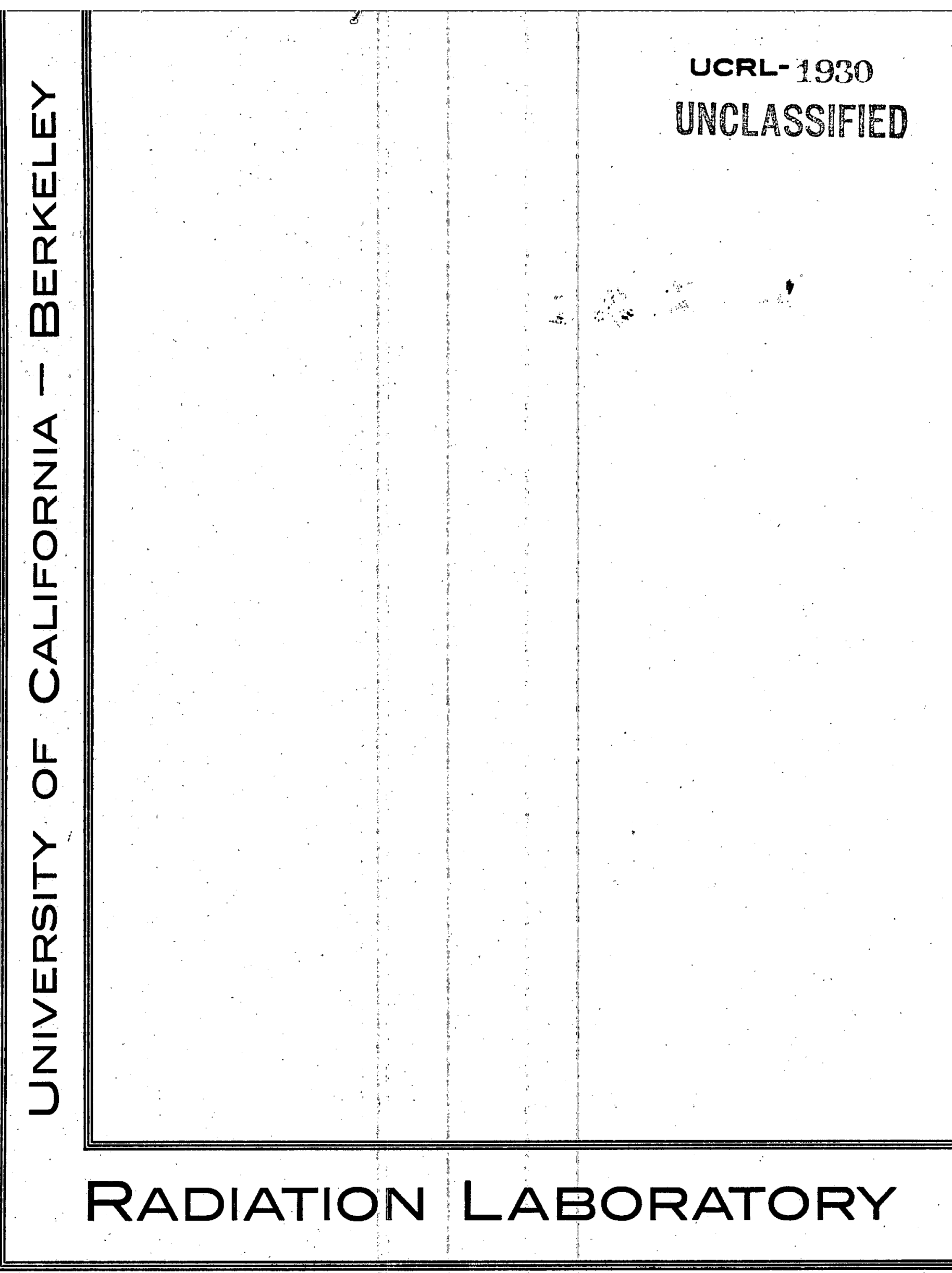




\section{DISCLAIMER}

This report was prepared as an account of work sponsored by an agency of the United States Government. Neither the United States Government nor any agency Thereof, nor any of their employees, makes any warranty, express or implied, or assumes any legal liability or responsibility for the accuracy, completeness, or usefulness of any information, apparatus, product, or process disclosed, or represents that its use would not infringe privately owned rights. Reference herein to any specific commercial product, process, or service by trade name, trademark, manufacturer, or otherwise does not necessarily constitute or imply its endorsement, recommendation, or favoring by the United States Government or any agency thereof. The views and opinions of authors expressed herein do not necessarily state or reflect those of the United States Government or any agency thereof. 


\section{DISCLAIMER}

Portions of this document may be illegible in electronic image products. Images are produced from the best available original document. 
$\underline{-1}$

Unclassified-Instrumentation Distribution

UNIVERSITY OF CALIFORNIA

Radiation Laboratory

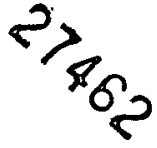

Contract No. W-7405-eng -48

\author{
A HIGH VACUUM HIGH SPEED ION PUMP \\ John S. Foster Jr., E. O. Lawrence and E. J. Lofgren \\ August 27, 1952
}


Unclassified-Instrumentation Distribution

A HIGH VACUUM HIGH SPEED ION PUMP

John S. Foster Jro, E。 O. Lawrence and E。 Jo Lofgren

Radiation Laborątory, Deparitiment of Phÿsices University of California, Berkeley, California

August 27, 1952

ABSTRACT

A vacuum pump based on the properties of a magnetically collinated electric discharge is described. It has a speed in the range 3000 to 7000 inters a seco ond and a base pressure in the order of $10^{-6}$ mo. 


\title{
A HIGH VACUUM HIGH SPEED ION PLMP
}

\author{
John S. Foster Jrog E。 Oo Lavrence and $E_{0}$. Loígren \\ Radiation Laboratory, Departiment, of Physics \\ University of California, Berkeley, California.
}

Augusest 27,1952

This report describes briefiy the salient features of a new type of vacuum pump. The general concept of an ion pump has occurrea to many investigators. The idea is to ionize the residual gas and to sweep it from the volume by some combination of electric and magnetic fields. It is, in fact, a fairly common obserration that gas pressure in a olosed system can be reduced by a discharge: however no previous ton pamp has had a base pressure or gas handling capacity comparable to laxge affuzon pumpso The main feas ture of this ion pump can be understood in terms of simple discharge phenomena.

\section{GENERAL DESCRIPTION}

A basic arrangement of the pump is shown in Figo Io The drawing has been divided into three main sections. Gas is removed from the low pressure center section, a nd delivered to the higher pressure exit sections. The active element in this operation I. an intense discharge whioh is collimated by magnetic field, and extends from a hot cathode to a cold reflecto ing cathode. This discharge is a type first used with cold cathodes by $F_{\circ} M_{0}$

Penning $^{2}$, and with a hot cathode by A. To Finkelstein ${ }^{3}$. Its essential characteristics is an efficient refluxing of the electrons. Electrons emitted from the hot filament are accelarated into the discharge where the nagnetic field confines their paths to tight helifes, permitting them to pass through the center section and be returned by the reflecting cathode. Thus, the electrons oscillate back and forth through the discharge, losing thelr energy by excitation and ionization until they are collected on the anode walls. The 
positive ions which are made during this process have a very low velocity compared to the electrons and a short mean free path: hence a positive space charge developes in the column. This space charge field moves the pcsitive ions to the cathode.

We have then a discharge containing a large flux of energetic electrons passing through the center section. Gas molecules enter the discharge because of their random motion and have a very good chance of being ionized there. The ionized molecules are then lateraliy confined by the magnetic field and delivered to the cathode by the plasma gradiento By means of this process, the gas pressure is reduced until an equilibrium is reached with in verse processes to be discussed in the next section.

On reaching a cathode, positive ions have several possible alter natives open to them. Some ions combine chemically with the cathode material. Other ions are neutralized at the cathode surface, and then as neutral particles they are unaffected by the magnetic field and can leave the discharge and enter the forevacuum system. Neutral particles attempting to travel back up the discharge are ionized again and returned to the cathode. Other neutral particles leaving the cathode are trapped on surfaces facing the cathode。 This is due to the gettering action of the cathode material which is constantiy being sputtered onto the neighboring surfaces. The quantity of gas which is removed by adsorption and chemistry is such that for steady operation under ordinary loads $(0.02 \mathrm{cc}$. NTP/sec。), the forevacuum system can be closed off. The maximum are current is limited by the positive ion current across the cathode sheath. At low pressures in the central region of the pump, the poso itive ion supply is insufficient to maintain a discharge of the desired character istics, (10 to 20 amperes at 300 to 400 volts) and it is necessary to introduce gasthrabialeak into the cathode region. This gas leak is adjusted to keep the pressure in the hot cathode region above $3 \times 10^{-4} \mathrm{~mm}_{0}$ The long anode constric- 
tion tube near the cathode is designed to confine the high gas pressure to the cathode region. The diameter of this tube is just slightly greater than the discharge, hence gas which might diffuse through the tube is ionized and returned to the cathode region. In this way, an intense discharge can be maintained even at the lowest gas pressure in the central region of the ion pump. While a minimum exit pressure is necessary to maintain a discharge for light pumping loads, any increase beyond that minimum merely increases the ion bombardment of the cathode. This ion pump is usually operated with an exit pressure of $305 \times 10^{-4} \mathrm{~mm}$, although exit pressures as high as $10^{-2} \mathrm{~mm}$ can be used. Within the range of exit pressures mentioned; the lowest center pressure may vary from $0.8 \times 10^{-6}$ to $6 \times 10^{-6} \mathrm{~mm}$.

\section{FACTORS IN THE SPEED AND BASE PRESSURE}

To determine the pumping speed one measures the equilibrium pressures at the entrance of the pump corresponding to different rates of gas flow into the pump. The speed, $S$, is then related to the change in gas leak rate $\Delta I$, and the corresponding change is pressure $\Delta \mathbf{P}$ by

$$
S=\frac{\Delta I}{\Delta P}
$$

The speed is ultimately limited by the surface area of the discharge itself. For a discharge of area $A$, the maximum speed would be:

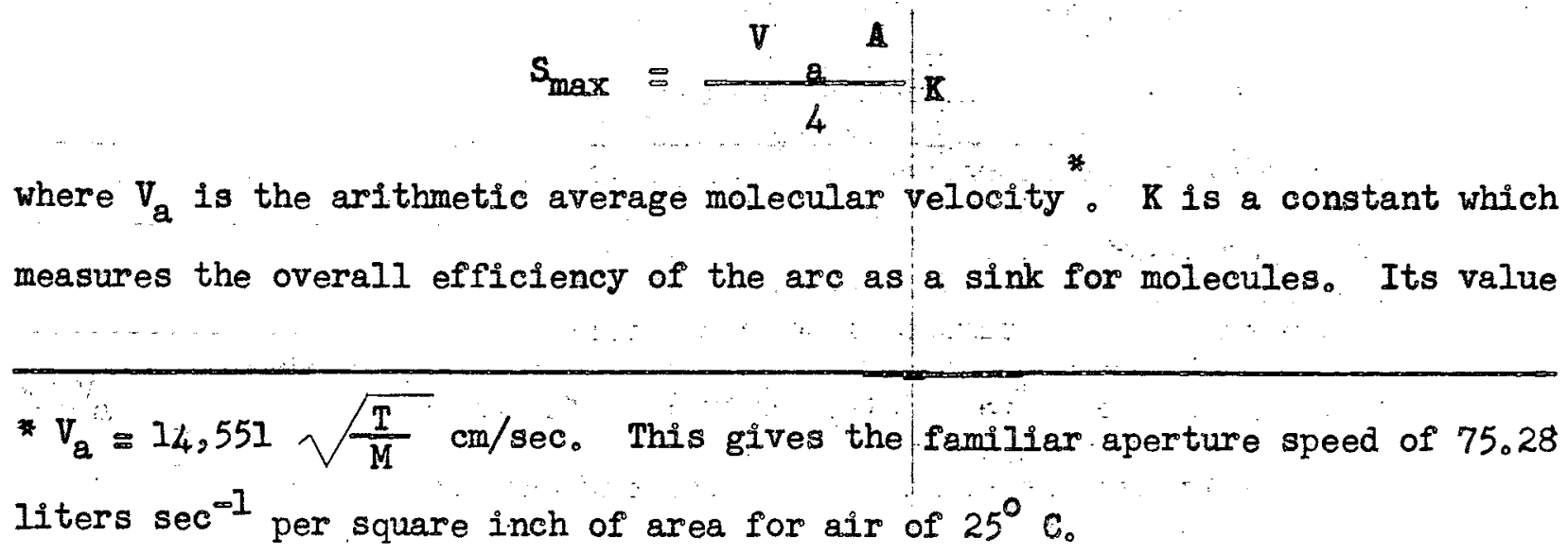


is usually about 0.5 . In addition, since the dascharge requires an axial magnetic field, there must be magnet windings around the discharge which at the same time provide adequate opening for the flow of gas to the discharge. Fig. 2 shows the general design of an ion pump which employs an open helix in the center section to maintain an axial magnetic field and still provides a large admittance.

When the pump is operated without an intentional gas leak at the center, there are several factors which can contribute to the residual pressure. There is always some outgassing of the local surfaces, but after a few hours of operation, the pressure is controlled more by the geometry of the pump and the adjustment of various electrical parameters. A portion of the gas pressure arises from jons which leave the discharge and become neutralized on the metal surfaces of the center section. However, most of the ions which leave the discharge migrate towards the ends of the pump in the space between the discharge and the walls and become neutralized on the outer porm. tion of the anode constriction tubes. The surfaces of these constrictions then become a source of gas particles which diffuse back toward the center section. The pump is made long enough so that there is a high probability that the neutral particles will be ionized again by the discharge before reaching the center section. Neutral atoms can also be formed in the discharge as a result of ion-electron attachment. This is normally considered a rare event in gaseous discharge, but can be of importance at low gas pressures and high ion densities.

The "internal" sources of pressure mentioned above are reduced by proper empirical manipulation of the controls. Variation of the hot cathode temperature determines the electron emission current and has some control over the rof plasma osciliations which are set up. These rf fields ${ }^{4}$ give 
rise to a very much higher ion arain across the magnetic field than would be expected from collision processes. The ion drain, of course, contributes to the residual pressure. The voltage applied to the discharge determines the initial electron energy, which in part, determines the relative importance of the ionization, excitation and recombination processes. The ratio of exit to center magnetic field determines the discharge diameter at the center, which in turn affects the drains, gas diffusion along the side tubes and pumping speed.

\section{III。 OPFRATING CHARACTERISTICS}

Several of these pumps have been made, each designed to provide better measurements and improved performance. One pump, Fig. 2, has been run with automatic controls continuously for two weeks, under a gas load of about $0,02 \mathrm{ce} / \mathrm{sec}$. (N.T.P.). This pump has been used to pump a 48,000 liter tank, starting at a pressure of $10^{-2} \mathrm{~mm}$. The lowest tank pressure varied with tank conditions from $5 \times 10^{-5} \mathrm{~mm}_{0}$ to $5 \times 10^{-6} \mathrm{~mm}_{0}$ The ion pump is not particularly sensitive to the type of gas, although inert gases are not consumed by chemical means, and forevacuum pumping is necessary. If an ion pump is allowed to pump on itself for a day, the difference between trapped and untrapped ion gauge readings of the center pressure is less than 10 percent。 Fig。 3 gives a typical speed curve for the pump shown in Fig. 2. Approximate operating conditions for this pump are listed in Table I. The total operating power for the conditions tabulated is about $42 \mathrm{KW}$.. This can be reduced to about $25 \mathrm{KW}$ at the expense of an increase in center pressure of a factor of two. The limit of continuous operation is set by the cathode and is roughly 2 to 4 weeks in the present designs. 


\section{TABLE I}

Pumping speed

Base pressure

Arc voltage

Arc current

Cathode

Magnet power
3000-7000 Iiters/sec.

$0.8 \times 10^{-6}$ to $5 \times 10^{-6} \mathrm{~mm}^{\circ}$

400-300 volts. 20-10 amps.

Radiantly heated tungsten cathode. Power consumed $4.5 \mathrm{KW}$.

Side magnets $20 \mathrm{KW}$

Center helix $12 \mathrm{KW}$

It is difficult to predict the degree of success that will be reached finally, since this development is less than a year old and a certain amount of engineering development remains to be done to achieve long term reliability and lower operating costs. The greatest advantage of the Ion pump over diffusion pumps is the complete absence of any extraneous working fluid. 'In some applications it is very important to avoid contamination from pumping fluid and elaborate and costly baffles must be provided. In evaluating the ion pump, the comparison should be made with conventional pumping systems, allowing for the reduced speed due to baffles and the increased operating cost including refrigerants. On this basis it may be concluded that ion pumps warrant further development.

A subsequent paper will give more details of the design and operation of the pump. Some observations on ion energies, densities, and drains made with this equipment will also be reported.

IV. ACKNOWLEDGEMENTS

During the course of this investigation, many people took an active interest in the work at various stages. It is a pleasure to acknowledge particularly the help of W. Bush, Paul Byerly, Warren Chupp, Bruce Cork, Warren Eukel, Forrest Fairbrother and H. Smith. 


\section{REFERENCES:}

1. Meyern, Wo V. Z. Physik v-84, p-531, 1933.

Schwarz, $H_{0}, Z_{0}$ Physik v $-122, p-437,1944$.

Cranston, F。 $P_{0}$ and Mann; Jo $K_{0}$, Microwave Laboratory, Stanford University, No. 101, Oct. 1949.

Champeix, Robert, Comptes Rendus No. I, July 3, 1950.

Early, H, Co and Dow, W. Go, Phy。 Rev, Vor 79, pol186, 1950.

2. Penning, F。 Mo, Physica V-4g p- $71_{2}, 1937$.

3. Finkelstein, A。 Tos R.S.I. $v=1 I_{2} p-94,1940$ 。

4. Bohm, David, "The Characteristics" of Electrical Discharges in Magnetic Fields." Nuclear Energy Series 1-5. 


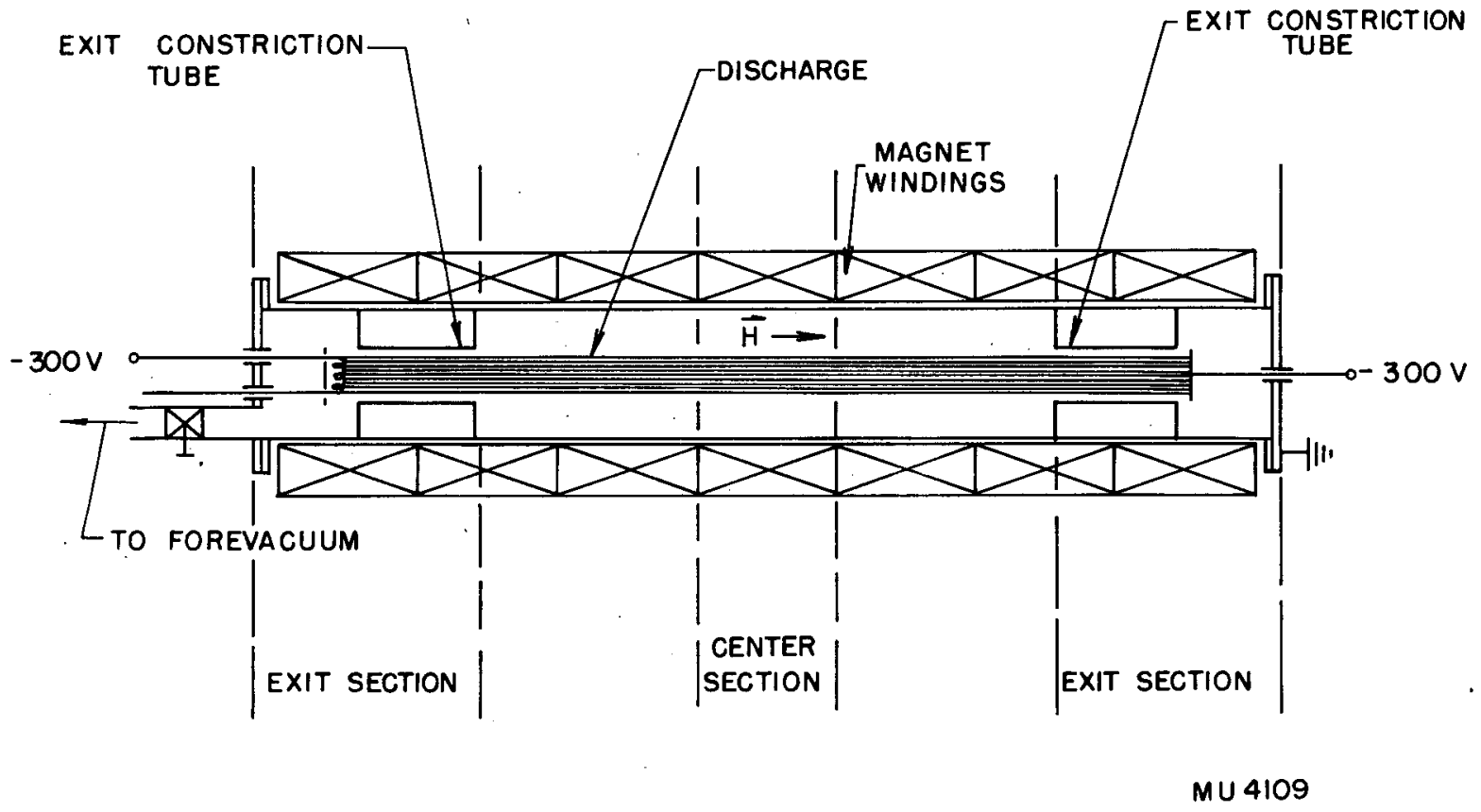

FIG. I 


\section{$1 /$}

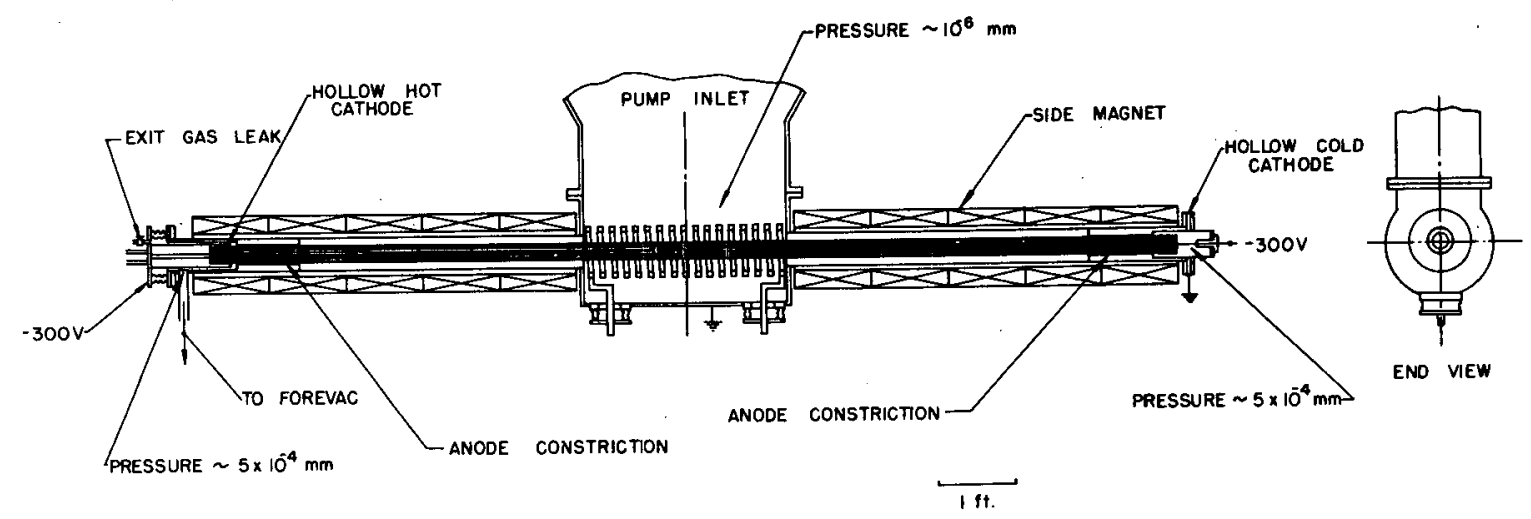

FIG. 2

MU 4110 

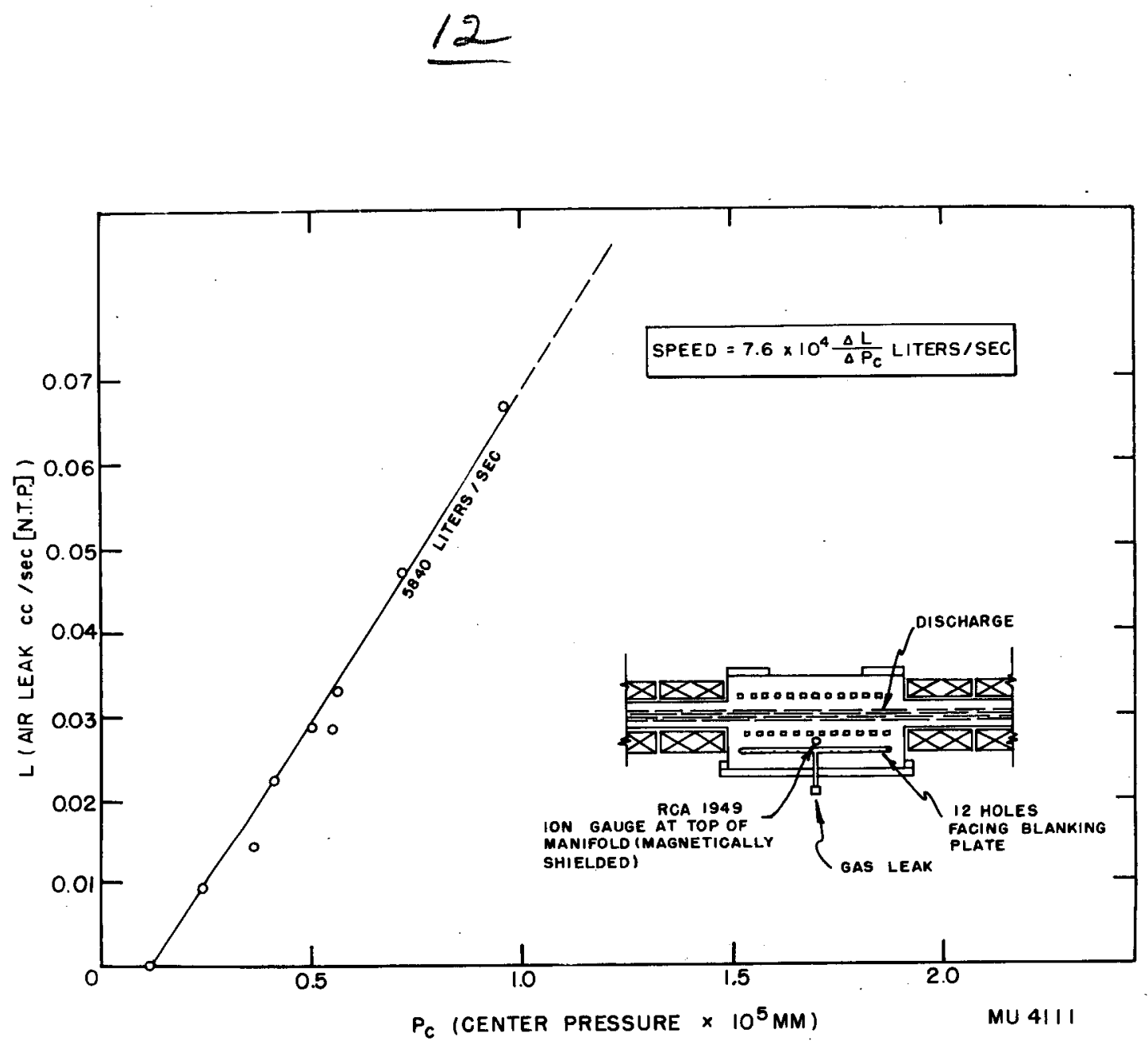

FIG. 3 